\section{Second Hand Smoking and Pediatric Hypertension - Need for Indian Studies}

\author{
Neha Sanwalka \\ Department of Nutrition and Biostatistics, \\ NutriCanvas, Mumbai, India
}

Received: June 15, 2016; Accepted: June 17, 2016; Published: June 23, 2016

Corresponding author: Neha Sanwalka

Prevalence of paediatric hypertension defined as average systolic blood pressure (SBP) and/or diastolic blood pressure (DBP) that is greater than or equal to the $95^{\text {th }}$ percentile for sex, age, and height on three or more occasions [1] is increasing globally including India. Hypertension was found in $7.6 \%$ of the 10,003 children studied from the Dibrugarh District in the North Eastern State of Assam, India [2]. In Surat city from Western State of Gujarat, India, $6.48 \%$ children were identified as having hypertension [3]. Similarly, in the Southern city of Bangalore, India, $8 \%$ children had high systolic BP where $2.7 \%$ children had high diastolic BP [4]. In urban city of Pune and rural village of Wadhra in Western State of Maharashtra, India, prevalence of hypertension was $5.6 \%$ and $5.75 \%$ respectively $[5,6]$. The studies hence indicate an increasing prevalence of paediatric hypertension in both urban and rural India.

Childhood obesity, sodium intake, insulin resistance, sleep apnoea, family history and excessive salt intake are some of the most commonly known and studied causes of paediatric hypertension [7]. However, second hand smoking or passive smoking is a lesser known and studied cause of hypertension in children. Very few studies from Iran, Germany and Italy have shown a significant effect of parental smoking or second hand smoking on pediatric hypertension [8-10]. Mean systolic blood pressure of elementary children in Iran exposed to tobacco has been found to be higher than the non-exposed group [8]. In another study from Germany, parental smoking was found to be a risk factor for higher blood pressure especially during exercise [9]. Parental smoking was associated with high systolic blood pressure even in Italian children [10]. However no such report analysing the effect of second hand smoking and paediatric hypertension in Indian population was found.

As per Global Adult Tobacco Survey (GATS) 2009-2010, 14\% of adults in India (24.3\% males and $0.8 \%$ females) were smokers [11]. The World Health Organization report on Cardiovascular harms from tobacco use and second hand smoke, 2012, states that China and India constitutes $40 \%$ of the world's smokers. The WHO report further highlights that $1 / 3^{\text {rd }}$ smokers $(38 \%)$ were unaware that smoking cause cardiovascular diseases and more neha.sanwalka@gmail.com contact@nutricanvas.com

Director of Nutricanvas, B 101-102, Velentine Apartment B3, Gen. A. K. Vaidya Marg, Malad (East), Mumbai 400097, India.

Tel: 918108009900

Citation: Neha Sanwalka. Second Hand Smoking and Pediatric Hypertension - Need for Indian Studies. J Clin Nutr Diet. 2016, 2:2.

than half (53\%) were unaware that smoking can cause stroke [12]. The WHO and GATS survey thus indicates the gap in knowledge regarding the cardio-vascular effects of smoking in adults. There is lack of data regarding knowledge of smokers and non-smokers about the effect of smoking on hypertension in either adults or children.

Hence, owing to high prevalence of smokers in India and increasing prevalence of paediatric hypertension, it is essential to undertake research study to analyse the percentage of children exposed to second hand smoking. It is also essential to study the effect of second hand smoking (parental and peer) on hypertension in Indian children. Public awareness campaigns regarding sideeffects of smoking in adults and children need to be planned to prevent the rise in paediatric hypertension in Indian children and raise awareness among masses. Public health policies need to be further tightened regarding sale of cigarettes and other smoke products especially in residential area and around educational institutes is essential.

To conclude, there is lack of data on effect of second hand smoking and hypertension in Indian children. Research study needs to be planned to assess the relationship of second hand smoking on paediatric hypertension in India. 


\section{References}

1 National Institutes of Health (2005) The fourth report on the diagnosis, evaluation, and treatment of high blood pressure in children and adolescents. U.S. department of health and human services.

2 Borah PK, Devi U, Biswas D, Kalita HCh, Sharma M, et al. (2015) Distribution of blood pressure \& correlates of hypertension in schoolchildren aged 5-14 years from North East India. Indian J Med Res 142: 293-300.

3 Buch N, Goyal JP, Kumar N, Parmar I, Shah VB, et al. (2011) Prevalence of hypertension in school going children of Surat city, Western India. J Cardiovasc Dis Res 2: 228-232.

4 Mishra PE, Shastri L, Thomas T, Duggan C, Bosch R, et al. (2015) Waist-to-Height Ratio as an Indicator of High Blood Pressure in Urban Indian School Children. Indian Pediatr 52: 773-778.

5 Kajale NA, Khadilkar AV, Chiplonkar SA, Khadilkar VV (2014) Body fat indices for identifying risk of hypertension in Indian children. Indian Pediatr 51: 555-560.
6 Taksande A, Chaturvedi P, Vilhekar K, Jain M (2008) Distribution of blood pressure in school going children in rural area of Wardha district, Maharashatra, India. Ann Pediatr Cardiol 1: 101-106.

7 Gulati S (2006) Childhood hypertension. Indian Pediatr 43: 326-333.

8 Seyedzadeh A, Hashemi F, Soleimani A (2012) Relationship between Blood Pressure and Passive Smoking inElementary School Children. Iran J Pediatr 22: 351-356.

9 Hacke C, Weisser B (2015) Effects of parental smoking on exercise systolic blood pressure inadolescents. J Am Heart Assoc 4.

10 Giussani M, Antolini L, Brambilla P, Pagani M, Zuccotti G, et al. (2013) Cardiovascular risk assessment in children: role of physical activity, family history and parental smoking on BMI and blood pressure. $J$ Hypertens 31: 983-992.

11 Ministry of Health and Family Welfare (2010) Global Tobacco Adult Survey (GATS) Fact Sheet 2009-2010.

12 World Health Organization (2012) Cardiovascular harms from tobacco use and secondhand smoke global gaps in awareness and implications for action. 